\title{
TROPOMI and TROPI: UV/VIS/NIR/SWIR instruments
}

\author{
P.F. Levelt ${ }^{\mathrm{a}}$, G.H.J. van den Oord $^{\mathrm{a}}$, M. Dobber ${ }^{\mathrm{a}}$, H. Eskes ${ }^{\mathrm{a}}$, M. van Weele ${ }^{\mathrm{a}}$, P. Veefkind ${ }^{\mathrm{a}}$, R. van \\ Oss $^{\mathrm{a}}$, I. Aben ${ }^{\mathrm{b}}$, R.T. Jongma ${ }^{\mathrm{b}}$, J. Landgraf $^{\mathrm{b}},{\text { J. de } \text { Vries }^{\mathrm{c}}, \text { H. Visser }}^{\mathrm{d}}$ \\ ${ }^{a}$ KNMI, PO Box 201, 3730 AE De Bilt, The Netherlands. \\ ${ }^{b}$ Netherlands Institute for Space Research SRON, Sorbonnelaan 2, 3584 CA Utrecht, The \\ Netherlands \\ ${ }^{c}$ Dutch Space BV, Newton weg 1, 2333 CP Leiden, The Netherlands \\ ${ }^{\mathrm{d}}$ TNO Science and Industry, Stieltjesweg 1, 2628 CK Delft, The Netherlands
}

\begin{abstract}
TROPOMI (Tropospheric Ozone-Monitoring Instrument) is a five-channel UV-VIS-NIR-SWIR non-scanning nadir viewing imaging spectrometer that combines a wide swath $\left(114^{\circ}\right)$ with high spatial resolution $\left(10 \times 10 \mathrm{~km}^{2}\right)$. The instrument heritage consists of GOME on ERS-2, SCIAMACHY on Envisat and, especially, OMI on EOS-Aura. TROPOMI has even smaller ground pixels than OMI-Aura but still exceeds OMI's signal-to-noise performance. These improvements optimize the possibility to retrieve tropospheric trace gases. In addition, the SWIR capabilities of TROPOMI are far better than SCIAMACHY's both in terms of spatial resolution and signal to noise performance.

TROPOMI is part of the TRAQ payload, a mission proposed in response to ESA's EOEP call. The TRAQ mission will fly in a non-sun synchronous drifting orbit at about $720 \mathrm{~km}$ altitude providing nearly global coverage. TROPOMI measures in the UV-visible wavelength region $(270-490 \mathrm{~nm})$, in a near-infrared channel (NIR) in the 710-775 $\mathrm{nm}$ range and has a shortwave infrared channel (SWIR) near $2.3 \mu \mathrm{m}$. The wide swath angle, in combination with the drifting orbit, allows measuring a location up to 5 times a day at 1.5 -hour intervals. The spectral resolution is about $0.45 \mathrm{~nm}$ for UVVIS-NIR and $0.25 \mathrm{~nm}$ for SWIR. Radiometric calibration will be maintained via solar irradiance measurements using various diffusers. The instrument will carry on-board calibration sources like LEDs and a white light source. Innovative aspects include the use of improved detectors in order to improve the radiation hardness and the spatial sampling capabilities. Column densities of trace gases $\left(\mathrm{NO}_{2}, \mathrm{O}_{3}, \mathrm{SO}_{2}\right.$ and $\left.\mathrm{HCHO}\right)$ will be derived using primarily the Differential Optical Absorption Spectroscopy (DOAS) method. The NIR channel serves to obtain information on clouds and the aerosol height distribution that is needed for tropospheric retrievals. A trade-off study will be conducted whether the SWIR channel, included to determine column densities of $\mathrm{CO}$ and $\mathrm{CH}_{4}$, will be incorporated in TROPOMI or in the Fourier Transform Spectrometer SIFTI on TRAQ.

The TROPI instrument is similar to the complete TROPOMI instrument (UV-VIS-NIR-SWIR) and is proposed for the CAMEO initiative, as described for the U.S. NRC Decadal Study on Earth Science and Applications from Space. CAMEO also uses a non-synchronous drifting orbit, but at a higher altitude (around $1500 \mathrm{~km}$ ). The TROPI instrument design is a modification of the TROPOMI design to achieve identical coverage and ground pixel sizes from a higher altitude. In this paper capabilities of TROPOMI and TROPI are discussed with emphasis on the UV-VIS-NIR channels as the TROPOMI SWIR channel is described in a separate contribution [5].
\end{abstract}

Keywords: Remote sensing, UltraViolet, Visible, Near Infrared, Troposphere

\section{INTRODUCTION}

The Ozone Monitoring Instrument (OMI) on NASA's EOS-Aura satellite, that was launched on 15 July 2004 , has demonstrated that tropospheric trace gas retrievals benefit tremendously from the combination of a large field-of-view and small ground pixels $\left(13 \times 24 \mathrm{~km}^{2}\right.$ at nadir) [1-4]. This combination optimizes the possibility for measuring cloud-free ground pixels. OMI is a UV-VIS imaging spectrometer covering the wavelength range 270 - $500 \mathrm{~nm}$ using three subchannels that are imaged on two Charge Coupled Devices (CCDs). Various results from OMI are shown in Figures 1-3. 
These examples include: the day-to-day variability of $\mathrm{NO}_{2}$ observed near-real time, forest fire detection in $\mathrm{NO}_{2}$ and aerosols, tropospheric ozone, $\mathrm{SO}_{2}$ emissions and an example of the small OMI footprint.
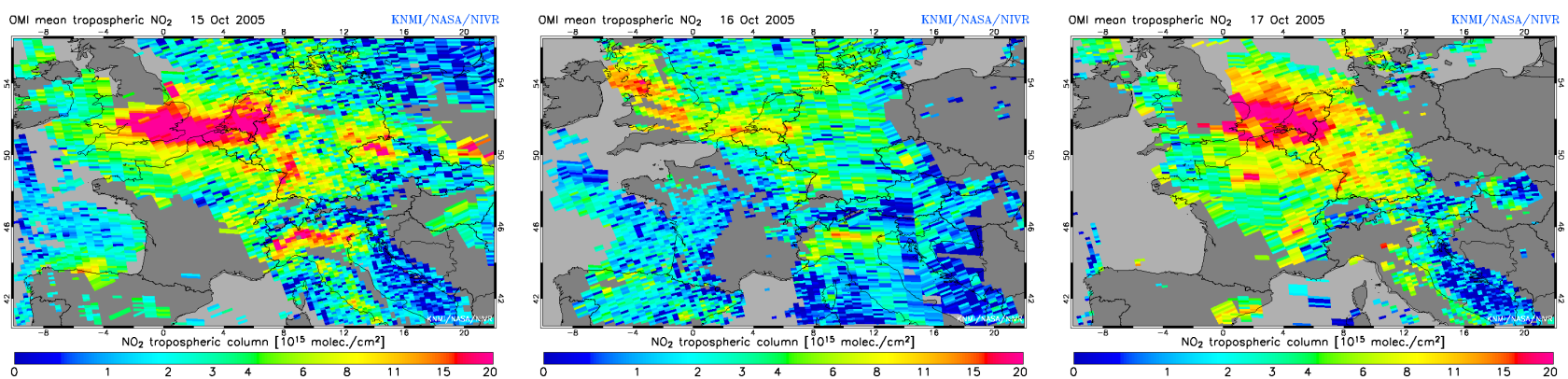

Fig. 1. Tropospheric $\mathrm{NO}_{2}$ distribution on Saturday 15 October 2005 (left), Sunday 16 October 2005 (middle) and Monday 17 October 2005 (right) based on near-real time OMI data. This product is available within 3 hours after the measurement. In the figures several overpasses are over plotted. Note the reduced pollution on Sunday 16 October. Courtesy Boersma, van der A, Eskes, Veefkind (KNMI)
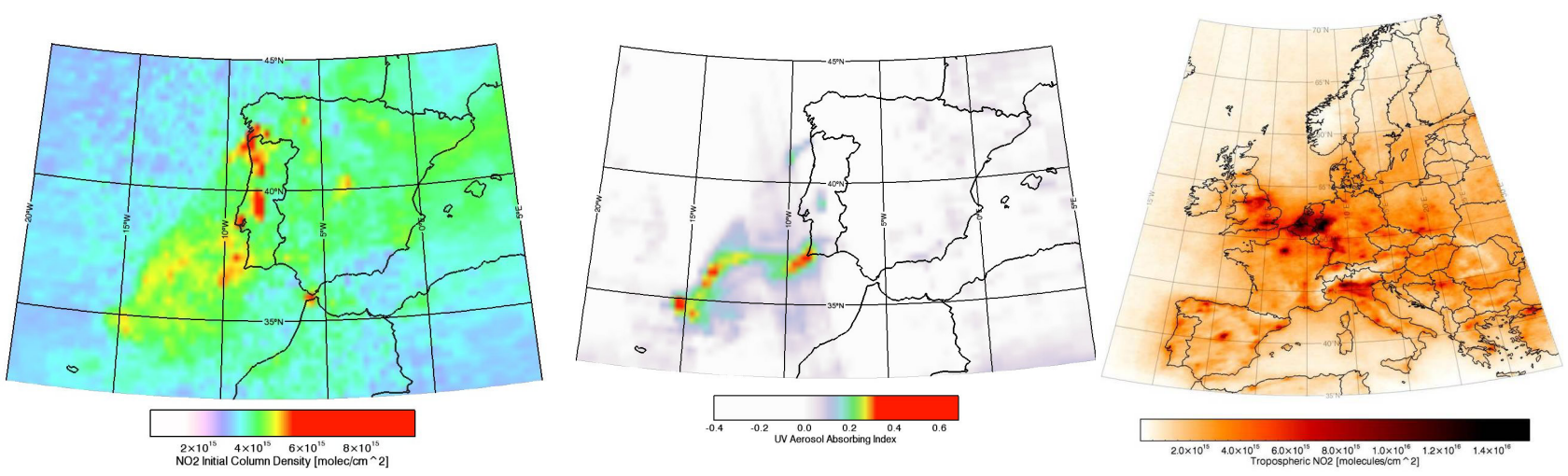

Fig. 2. $\mathrm{NO}_{2}$ (left) and aerosol (middle) distributions on 21 August 2005 related to the forest fires in Portugal. The right panel shows the $\mathrm{NO}_{2}$ distribution for the May-September 2005 period.

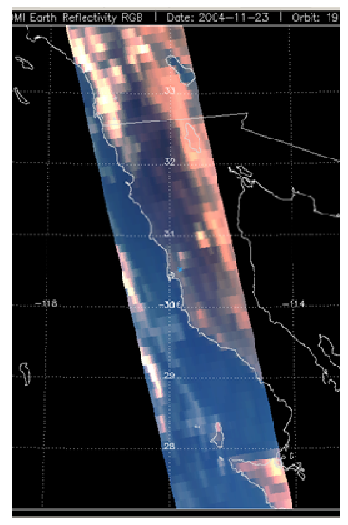

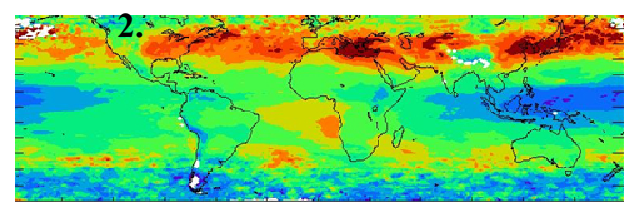

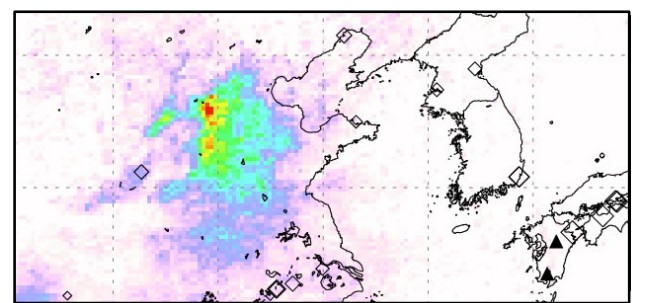

Fig. 3. Left: OMI superzoom measurements of Baja California with $13 \mathrm{~km} \times 3 \mathrm{~km}$ ground pixels, comparable to the resolution of TROPOMI-TROPI. In super-zoom mode OMI has degraded signal to noise and therefore during standard operations 8 of these pixels are binned.

Top right: Tropospheric ozone distribution for July 2005 based on combining Aura OMI columns and MLS profile results (courtesy Ziemke \& Bhartia, NASA-GSFC).

Bottom right: $\mathrm{SO}_{2}$ over China observed with OMI (courtesy Krotkov, NASA-GSFC) 


\section{SCIENCE DEFINITION}

In order to prepare for the period after 2010, when OMI on Aura and SCIAMACHY on Envisat have reached their endof-life, the OMI and SCIAMACHY participating parties in the Netherlands started user consultations to identify the scientific user requirements for future missions. The resulting requirements basically focus on three science aspects:

- The time scales for air quality change on global and regional scale

․ The strength and distribution of sources and sinks of trace gasses and aerosols.

- The role of tropospheric compositions in global changes.

In the remainder of this section we provide a summary of the science rationales that served as input for the development of a new instrument.

\subsection{The time scales of air quality change on a global and regional scale}

Local air pollution conditions are determined by both local sources and sinks and by long-range transport of pollutants. These aspects are the prime drivers for having an instrument with daily global coverage and a small footprint, since both local and global measurements are needed.

Megacities are known to suffer from photochemical smog. In the formation of photochemical smog, the primary pollutants are nitrogen oxides $\left(\mathrm{NO}_{\mathrm{x}}\right), \mathrm{CO}$ and volatile organic compounds (VOCs), which rapidly convert into secondary pollutants. The most important secondary pollutant is ozone; others include oxidised hydrocarbons, e.g. formaldehyde $(\mathrm{HCHO})$, and photochemical aerosols. Emissions of the so-called ozone precursor gases, like tropospheric $\mathrm{NO}_{2}$ (Figure 1) and particulate matter arise from a variety of sources including combustion processes (energy production, industry, transportation and biomass burning) and agricultural practices. As a consequence, high levels of ozone and aerosols are observed over polluted continental regions. Since the photochemical lifetime of $\mathrm{O}_{3}$ and $\mathrm{CO}$ can be more than one month in the free troposphere, transport from source to remote regions affects the background levels on a large scale.

Local and regional air quality varies on typical time scales of hours. These changes are related to a variety of processes like the build-up of the boundary layer, fronts, convection, variations in the actinic flux and surface emissions (rush hour, combustion processes), and processes like the formation of ozone and the residence time of $\mathrm{NO}_{2}$. The $\mathrm{OMI}$ instrument, that has a polar orbit, is already capable to make multiple measurements at higher latitudes because of its wide swath. These measurements have a fixed time separation of 98 minutes, and are not distributed over the day and over the latitudes with high population areas like Europe Northern America and China. In order to improve the time sampling over the day over highly populated areas the drifting orbit is introduced.

Legislation in Europe is aimed to reduce ozone, nitrogen-dioxide and PM. The objectives of this legislation can be counteracted by the transport of ozone and its precursors from North America in combination with chemical processing over the Atlantic Ocean. In a similar way background concentrations over the Pacific and North America are determined by export of pollutants from Asia. The rapid economical growth in Asia calls for a monitoring of the intercontinental transport in order to be able to evaluate the effects of legislation. The long-range transport is driven by the transport of pollutants from the boundary layer into the free troposphere. This information can be obtained by measuring the ozone profile and elevated aerosol concentrations in the low troposphere

\subsection{The strength and distribution of sources and sinks of trace gases and aerosols.}

A proper understanding of air quality and tropospheric composition in general requires the quantification of the strength, distribution and variability of emissions of $\mathrm{NO}_{\mathrm{x}}, \mathrm{CO}$, aerosols, $\mathrm{SO}_{2}, \mathrm{CH}_{4}$ and volatile organic compounds, and to identify the contribution of the different source categories, such as fossil fuel burning, agriculture, and natural emissions such as lightning. This should be complemented with a quantification of the rate and location of removal by chemical transformation in the atmosphere (oxidizing capacity), wet removal and dry deposition. Tropospheric ozone plays a critical role in the control of the oxidizing capacity of the atmosphere because of its role in the formation of the hydroxyl radical $(\mathrm{OH})$, the primary cleansing agents of the lower atmosphere. The precursors of ozone are $\mathrm{CO}^{2}$ and $\mathrm{NO}_{2}$. By studying $\mathrm{CO}, \mathrm{NO}_{2}$ and ozone information about the $\mathrm{OH}$ budget can be derived. 


\subsection{The role of tropospheric compositions in global changes.}

The third science issue addressed concerns a better understanding of the radiative, physical and chemical impact of changes in tropospheric composition. In particular, the climate impact of primary pollutants (aerosols, $\mathrm{CH}_{4}$ ) and the transformation of precursors (especially $\mathrm{NO}_{2}, \mathrm{SO}_{2}, \mathrm{CO}$ and $\mathrm{VOCs}$ ) into radiatively active constituents, including $\mathrm{CO}_{2}$, $\mathrm{O}_{3}$ and secondary aerosols. Methane, tropospheric ozone and aerosols show a strong temporal and spatial variability and directly affect the radiation budget. Methane and tropospheric ozone contribute considerably to radiative forcing (30\%) which is not negligible compared to the contribution by the well-known greenhouse gas $\mathrm{CO}_{2}(53 \%)$. Moreover, the oxidation of $\mathrm{CO}$ and $\mathrm{CH}_{4}$ is an important source of $\mathrm{CO}_{2}$.

VOCs, $\mathrm{NO}_{2}$ and $\mathrm{SO}_{2}$ are important precursors of man-made aerosols, while formaldehyde (HCHO) is an oxidation product of VOCs. On the other hand, several of these trace gasses are also produced by natural processes like the emissions of active volcanoes.

\section{SCIENTIFIC REQUIREMENTS}

Based on the scientific rationales a list of key products has been compiled together with the required accuracies (see Table 1). Column densities of trace gases $\left(\mathrm{NO}_{2}, \mathrm{O}_{3}, \mathrm{SO}_{2}\right.$, and $\left.\mathrm{HCHO}\right)$ will be derived primarily using the Differential Optical Absorption Spectroscopy (DOAS) method. The spectral windows and algorithms used are essentially the same as those used for OMI-Aura. The uncertainty of the derived columns depends on the Signal to Noise $(\mathrm{S} / \mathrm{N})$ ratio and on the air mass factor (AMF). The AMF is the number of trace gas molecules encountered along an average light path relative to the total column, and depends on the scenario considered.

In order to arrive at $\mathrm{O}_{3}$ and $\mathrm{NO}_{2}$ tropospheric columns from the DOAS slant columns, first the stratospheric contribution to the slant columns needs to be estimated. For $\mathrm{NO}_{2}$, this is achieved by assimilating slant columns into a chemistry transport model for regions with negligible tropospheric $\mathrm{NO}_{2}$, i.e., over remote oceans. For $\mathrm{O}_{3}$, the stratospheric contribution is derived from assimilated ozone profiles. Then, the stratospheric contribution is subtracted from the slant column, and the residue is divided by the tropospheric air mass factor.

The uncertainties in the trace gas products have been estimated for a nominal and a minimum scenario. For the UV-VisNIR products the definition is as follows: For the nominal scenario, an average viewing geometry was selected, corresponding to a geometrical AMF of 3, and a fairly large $\mathrm{S} / \mathrm{N}$ ratio (2000 - 1500; some clouds present in the pixel). For the minimum scenario, the geometrical AMF is 2, corresponding to a nadir view in the tropics, and the $\mathrm{S} / \mathrm{N}$ is (1500 - 1000; no clouds present in the pixel). The assumed surface albedo is 0.02 (dark, effectively a lower limit) in both scenarios. Except for the total $\mathrm{O}_{3}$ and $\mathrm{NO}_{2}$ column product, the air mass factor is one fourth of the geometrical air mass factor, because only those photons that penetrate deep into the troposphere and travel back to the sensor carry information on the troposphere. For moderate pollution, the accuracy of the tropospheric columns of $\mathrm{NO}_{2}, \mathrm{O}_{3}, \mathrm{SO}_{2}$, and HCHO are estimated to be $15 \%-25 \%, 20 \%-40 \%, 30 \%-40 \%$, and $30 \%-60 \%$, respectively. Here the first number refers to the nominal and the second number to the minimal scenario. The accuracies include the uncertainty related to random instrument noise (Table 1) and all other errors, e.g. profile assumptions in case of profile retrieval and systematic instrument effects. For the SWIR products $\left(\mathrm{CO}\right.$ and $\left.\mathrm{CH}_{4}\right)$ the nominal conditions correspond to an atmospheric scene with a solar zenith angle of 50 degrees and a surface albedo of 0.2 . The minimum scenario corresponds to a solar zenith angle of 70 degrees and surface albedo of 0.05 .

The main purpose of the aerosol algorithm is to obtain more information on aerosols in the UV part of the spectrum, The TROPOMI aerosol product is derived with the OMI-Aura algorithm, but with the following improvements: the surface albedo database is replaced with measured surface albedo information, and altitude information on aerosol layers is obtained from the $\mathrm{O}_{2}$ A band measurement. 


\begin{tabular}{|c|c|c|c|}
\hline \multirow{3}{*}{$\begin{array}{l}\text { Key Observables } \\
\mathrm{NO}_{2}\end{array}$} & \multirow{2}{*}{$\begin{array}{l}\text { Product Type } \\
\text { Total Column } \\
\end{array}$} & \multicolumn{2}{|c|}{$\begin{array}{c}\text { Uncertainty, relative numbers } \\
\text { Nominal }^{2)}\end{array}$} \\
\hline & & $2 \%$ & $3 \%$ \\
\hline & Tropospheric Column & $6 \%$ & $13 \%$ \\
\hline \multirow[t]{2}{*}{$\mathbf{O}_{3}$} & Total Column & $0.5 \%$ & $2 \%$ \\
\hline & Tropospheric Column & $15 \%$ & $35 \%$ \\
\hline $\mathrm{CO}$ & Total Column $^{1)}$ & $6 \%$ & $19 \%$ \\
\hline $\mathrm{SO}_{2}$ & Total Column ${ }^{1)}$ & $5 \%$ & $10 \%$ \\
\hline НCHO & Total Column ${ }^{1)}$ & $25 \%$ & $55 \%$ \\
\hline \multirow[t]{2}{*}{$\mathrm{CH}_{4}$} & Total Column $^{1)}$ & $0.1 \%$ & $0.5 \%$ \\
\hline & & \multicolumn{2}{|c|}{ Accuracy } \\
\hline \multirow[t]{3}{*}{ Aerosol } & AOT (UV wavelengths) & \multicolumn{2}{|c|}{$15 \%$} \\
\hline & Single scattering albedo (UV wavelengths) & \multicolumn{2}{|c|}{0.05} \\
\hline & Aerosol absorption index & \multicolumn{2}{|c|}{$1 \%$} \\
\hline
\end{tabular}

Table 1. TRAQ performances for total and tropospheric column retrievals under cloud-free conditions. Uncertainty refers to the relative uncertainties related to instrument $S / N$. The uncertainties pertain to the following column densities for $\mathrm{NO}_{2}, \mathrm{SO}_{2}, \mathrm{HCHO}, \mathrm{CO}$ and $\mathrm{CH}_{4}$ respectively: $510^{15}, 410^{16}, 410^{16}, 110^{18}$ and $3.810^{19}$ [molecule $/ \mathrm{cm}^{2}$ ]. The total column is $300 \mathrm{DU}$ and the tropospheric column is $20 \mathrm{DU}$ for $\mathrm{O}_{3}$. Accuracies are discussed in the text, but are given here for the aerosol products because uncertainties, which are related to $S / N$, are not the driving factor. The total column is about equal to the tropospheric column for $C$, $H C H O$, $\mathrm{CH}_{4}$, and $\mathrm{SO}_{2}$. For $\mathrm{SO}_{2}$ there is a stratospheric contribution during short periods after volcanic eruptions. Nominal and minimum for the different products are defined in the text.

\section{TECHNICAL IMPLEMENTATION}

After consolidation of the science requirements a design phase was started for an instrument called TROPOMI. Evaluation of the science requirements showed that for the $270-500 \mathrm{~nm}$ range the requirements showed considerable agreement with the performance of the OMI instrument apart from the fact that this performance has to be met for smaller ground pixels. Also, the in-flight performance of OMI shows that the CCDs are prone to radiation effects, in particular from high-energetic protons $(>10 \mathrm{MeV})$ trapped in the magnetic field of the earth. This manifests itself in an increase of the dark current of pixels, RTS behaviour and transient pixels. For all these effects solutions have been implemented in the operational data processing software but in the new instrument the detector operating temperature is lowered to make these effects less manifest.

Tropospheric retrievals can be improved, with respect to OMI retrievals, by having accurate surface albedo, cloud and aerosol information. This requires the addition of a Near-InfraRed (NIR) channel in the range $710-775 \mathrm{~nm}$.

Finally, measurement of $\mathrm{CO}$ and $\mathrm{CH}_{4}$ require the addition of a Short-Wavelength InfraRed (SWIR) channel with far more stringent thermal requirements. For that purpose it was decided to implement the SWIR channel as a separate module with an independent telescope aperture. Details of the SWIR module are given in [5].

Based on the above improvements over OMI two flavours of a new generation monitoring instrument have been developed: TROPOMI and TROPI. Both are five-channel (UV1, UV2, VIS, NIR and SWIR) imaging spectrometers with a modular design.

TROPOMI is proposed to fly on TRAQ, a mission proposed in response to ESA's EOEP call. TRAQ will fly in a nonsun-synchronous drifting orbit (altitude $720 \mathrm{~km}$, inclination $57^{\circ}$ ) providing nearly global coverage. This allows measuring locations up to 5 times a day at 1.5 hour intervals. The other instruments that will fly on TRAQ are 
SIFTI/CLIM and OCAPI. A trade-off study will be conducted whether the SWIR channel will be incorporated in TROPOMI or in the Fourier Transform Spectrometer SIFTI on TRAQ.

The TROPI instrument is similar to the complete TROPOMI instrument (UV-VIS-NIR-SWIR) and is proposed in the CAMEO initiative, as described for the U.S. NRC Decadal Study on Earth Science and Applications from Space. CAMEO also uses a non-sun-synchronous drifting orbit, but at a higher altitude. The other instruments on CAMEO are a scanning MLS instrument and a thermal IR instrument.

Table 2 shows the technical details and performance parameters of TROPOMI and TROPI.

\begin{tabular}{|c|c|c|c|c|c|}
\hline & UV1 & UV2 & VIS & NIR & SWIR \\
\hline Range & $270-320 \mathrm{~nm}$ & $300-400 \mathrm{~nm}$ & $380-490$ & $710-775 \mathrm{~nm}$ & $2305-2385 \mathrm{~nm}$ \\
\hline Resolution & $1.1 \mathrm{~nm}$ & $0.45 \mathrm{~nm}$ & $0.52 \mathrm{~nm}$ & $0.45 \mathrm{~nm}$ & $0.25 \mathrm{~nm}$ \\
\hline Sampling & $\sim 0.4 \mathrm{~nm}$ & $0.15 \mathrm{~nm}$ & $\sim 0.18 \mathrm{~nm}$ & $0.15 \mathrm{~nm}$ & $0.125 \mathrm{~nm}$ \\
\hline Signal-to-Noise & $\geq 100-1000$ & $\geq 1000$ & $\geq 1500$ & $\geq 100-500$ & $>100$ \\
\hline Ground pixel & $\geq 16 \times 40 \mathrm{~km}^{2}$ & \multicolumn{3}{|c|}{$\geq 8 \times 10 \mathrm{~km}^{2}$} & $\geq 10 \times 10 \mathrm{~km}^{2}$ \\
\hline Swath & \multicolumn{4}{|c|}{$2600 \mathrm{~km}$ for TROPOMI and $4700 \mathrm{~km}$ for TROPI } & $2600 \mathrm{~km}$ \\
\hline Dimension & \multicolumn{4}{|c|}{$0.56 \times 0.45 \times 0.38 \mathrm{~m}^{3}$} & $0.45 \times 0.3 \times 0.2 \mathrm{~m}^{3}$ \\
\hline Mass & \multicolumn{4}{|c|}{$35 \mathrm{~kg}$} & $17 \mathrm{~kg}$ \\
\hline Temp. optics & \multicolumn{4}{|c|}{$283 \mathrm{~K}$} & $220 \mathrm{~K}$ \\
\hline Temp. detector & \multicolumn{4}{|c|}{$233 \mathrm{~K}$} & $165 \mathrm{~K}$ \\
\hline
\end{tabular}

Table 2. Technical details and performance parameters for the TROPOMI-TROPI instruments. The signal-to-noise values are for minimum radiance conditions and exceed those of OMI for smaller ground pixels. The mass and dimensions are estimates for the telescope and detectors without the thermal hardware.
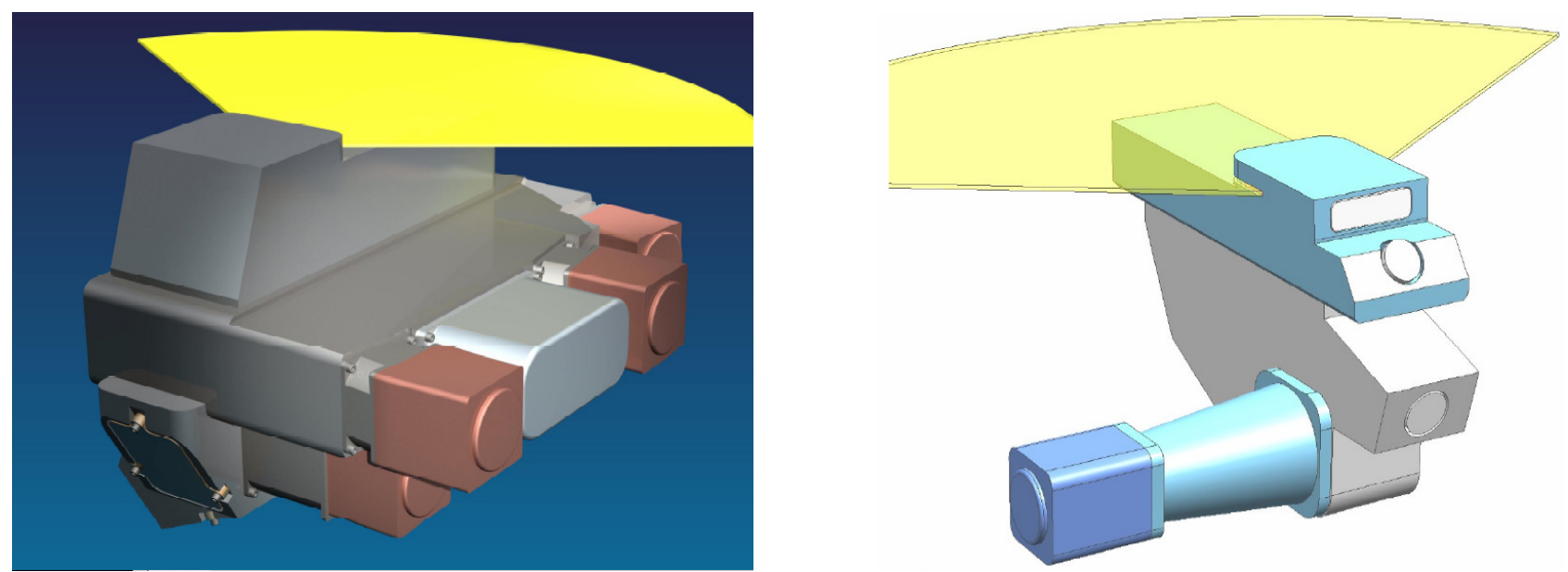

Fig. 4. UV-VIS-NIR module (left) and SWIR module (right). The fields-of-view are indicated in yellow.

In the design of the optical system an important concept of the OMI design, minimization of the difference between the light paths for radiance and irradiance measurements, has been included: As a consequence, the instrument BSDF is relative insensitive to in-flight degradation because radiance and irradiance are affected simultaneously. 
TROPOMI will use the same in-flight calibration sources as OMI [2] because these turn out to be sufficient to perform all the necessary in-flight characterizations. TROPOMI will include a White Light Source, Light Emitting Diodes near the detector and use the Sun for radiometric and spectral calibration. TROPOMI will have several on-board diffusers to be used for irradiance measurements. At least there will be one quartz volume diffuser because of the excellent performance in the OMI program and, especially, because this type of diffuser generates only very small amplitude spectral and spatial diffuser features that affect retrievals. OMI has two back-up aluminium diffusers, next to the volume diffuser but for TROPOMI/TROPI it may be decided to add an additional volume diffuser at the expense of an aluminium diffuser. Imaging spectrometers like OMI are able to easily detect the significant features introduced by Aluminium diffusers. These features are detrimental for accurate retrievals of, in particular, weakly absorbing trace gases. The TROPOMI optical design will be optimized to reduce diffuser features.

Both TROPOMI and TROPI will be in a drifting orbit. This implies that, in order to maintain a cold side on the spacecraft, every few weeks a yaw-flip manoeuvre will have to be executed. OMI is flying in a polar orbit and can observe the Sun every orbit near the North Pole by looking in backward direction. For a drifting orbit the chances for observing the Sun are less well conditioned and re-design of the solar calibration optics is required. Various design options are under consideration. The preferred option will depend on the actual location of TROPOMI on the spacecraft.

An important selection that still needs to be made is whether the UV-VIS-NIR detector modules for TRAQ will be equipped with CCD or CMOS-APS technology. For the SWIR module only hybrid CMOS detector can be used. For TROPI on CAMEO both the UV-NIR and the SWIR detector will be CMOS based because of the harsh radiation environment.

In order to maintain a compact design for the SWIR module immersed grating technology will be used. At this moment it is not clear whether the SWIR channel will contain a polarization scrambler. In order to arrive at a definitive choice simulations are currently performed and the effect of a scrambler at the SWIR wavelengths will likely be studied in a bread board of the channel.

The requirements for small ground pixels and multiple measurements per day are the main design drivers for TROPOMI and TROPI. Figure 5 shows that for tropospheric retrievals the gain of the TRAQ orbit over GOME-2 and SCIAMACHY is indeed considerable. Figure 6 shows that sampling of up to 5 times per day is possible with TRAQ.
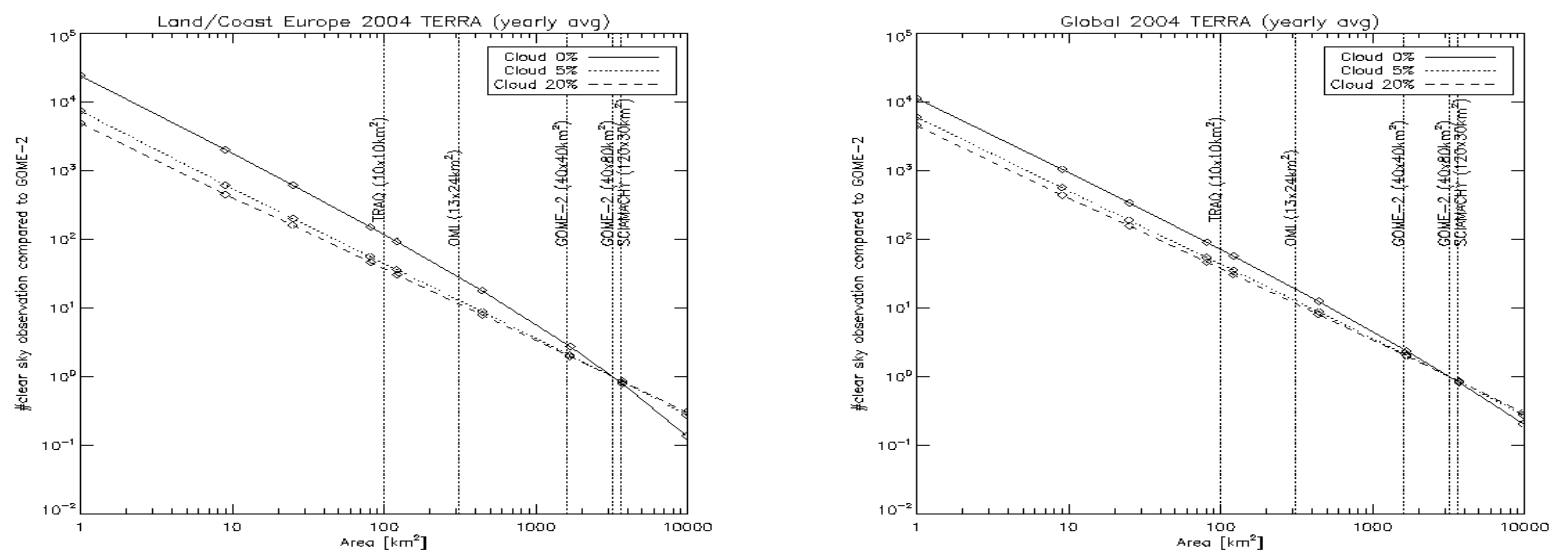

Fig. 5. The overall gain factor in cloud-free observations for TROPOMI and SIFTI pixel sizes is 109 (Europe over land) and 98 (global) in comparison to GOME-2, and 260 (Europe over land) and 232 (global) in comparison with SCIAMACHY $(2.4 \mu \mathrm{m})$, assuming identical swaths. This implies roughly that with the TRAQ pixel sizes the sampling in one to three days corresponds with what can be achieved with GOME-2 and SCIAMACHY in one year. If we allow for $20 \%$ cloud-cover as many tropospheric observations are obtained within one day as GOME-2 achieves in one month. 


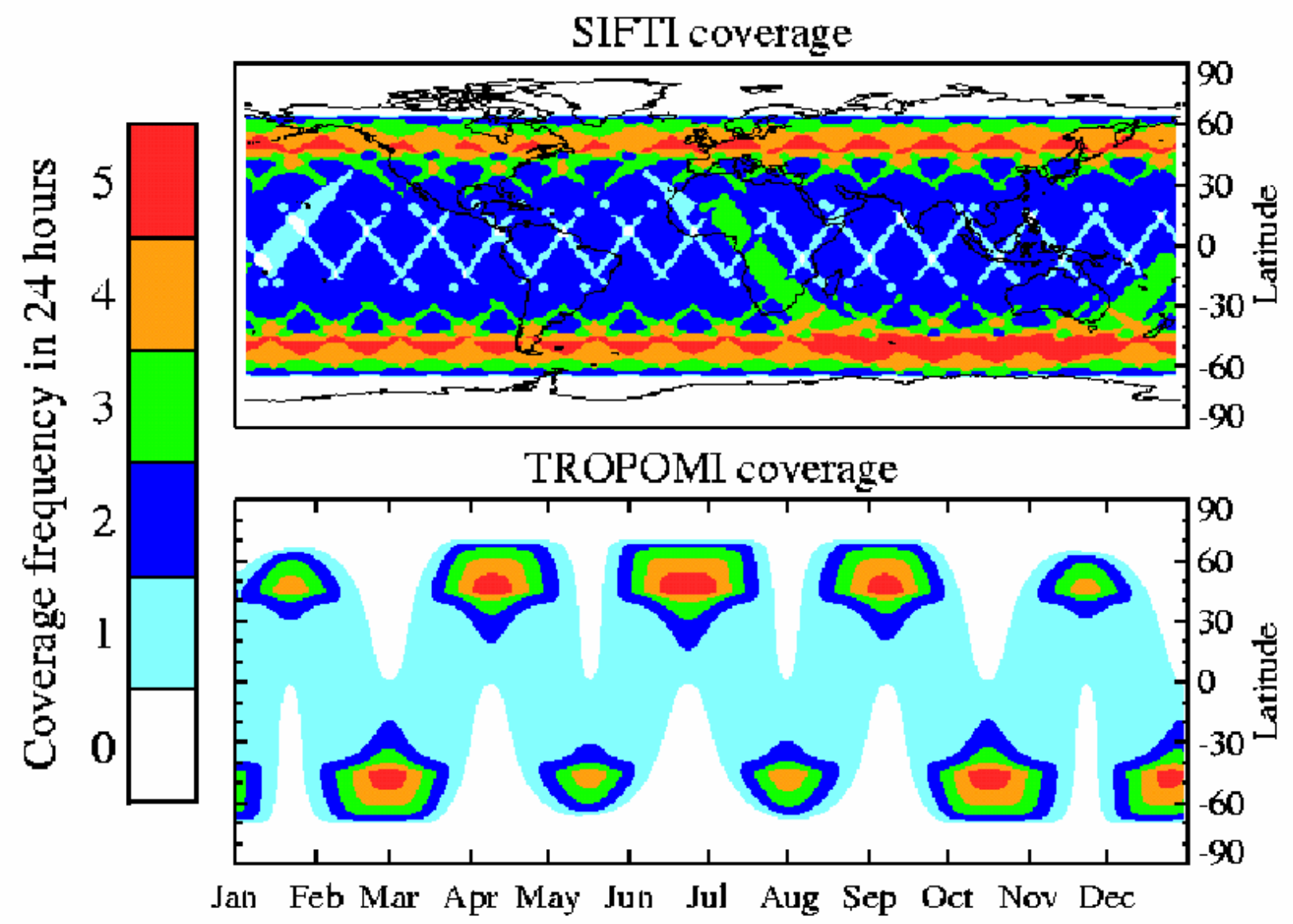

Fig 6. Revisit frequencies for TROPOMI and SIFTI on TRAQ. Courtesy Nathaniel Livesey (NASA-JPL)

\section{CALIBRATION}

Based on the OMI-SCIAMACHY experience the on-ground calibrations will be performed under in-flightrepresentative conditions in Thermal Vacuum. The calibration will be traceable to standards by using NIST FEL lamps and an integrating sphere. Various dedicated stimuli designed for the calibration of OMI will be further optimized. These include a White Light Source (Sun simulator), a Star Stimulus (geolocation and FOV calibration), a Linearity and Stray Light Stimulus and an Echelle Stimulus (slit function and wavelength calibration). The in-flight calibration measurements [2] will be fully integrated in the operations concept and processed in a dedicated facility, like for OMI. The instrument will carry on-board calibration sources like Light Emitting Diodes and a white light source. These will be used for detector and electronics calibration. Radiometric calibration will be maintained via solar irradiance measurements using various on-board diffusers. Because of the drifting orbits the spacecraft will regularly execute a yaw-flip maneuver in order to maintain a cold side. A special mechanism has been developed to accommodate regular solar observations from these types of orbits. Care has been taken to have almost identical light paths for radiance and irradiance to minimize the effect of in-flight degradation. 


\section{CONCLUSIONS}

As a follow-up of the OMI and SCIAMACHY instruments, various parties in the Netherlands have designed two new instruments TROPOMI and TROPI to fly on the TRAQ and CAMEO mission, respectively. The UV/VIS/NIR module contains considerable heritage from the OMI instrument. The SWIR module contains heritage from both OMI and SCIAMACHY. The TRAQ mission was recently selected by ESA for further study. In its baseline configuration TRAQ contains the TROPOMI instrument without the SWIR module. A trade-off study will be performed to decide if the SWIR TROPOMI module will be incorporated in TRAQ or the French SIFTI-SWIR channel. Various parties in the Netherlands are currently developing a bread board of the TROPOMI SWIR channel for a feasibility and performance demonstration.

The OMI instrument was developed and is operated under the lead of the Royal Netherlands Meteorological Institute (KNMI). Various concepts and facilities that were developed for OMI [4] will be re-used for the UV/VIS/NIR module. Among these are a processing facility (OMI Dutch Processing System, ODPS), a fully automated in-flight calibration facility (Trend Monitoring and Calibration Facility, TMCF). Also the operational software for Level 0 to Level $1 \mathrm{~b}$, and to higher Level products, can be re-used with minor modifications. This has the advantage that lessons-learned from OMI are automatically implemented for TRAQ and CAMEO. This provides an enormous benefit because the development of these facilities and operational software took about 5 years to complete while adjusting for the TRAQ/CAMEO missions will require far less.

\section{ACKNOWLEDGEMENTS}

The authors like to thank the Netherlands Agency for Aerospace Programmes (NIVR) for financial support and NASAJPL (Nathaniel Livesey) for providing Figure 6.

\section{REFERENCES}

[1] P.F. Levelt at al. (2006), Science Objectives of the Ozone Monitoring Instrument, IEEE Trans. Geo. Rem. Sens. Vol. 44, No. 5, 1199-1208, doi:10.1109/TGRS.2006.872336.

[2] M.R. Dobber et al. (2006), Ozone Monitoring Instrument Calibration, IEEE Trans. Geo. Rem. Sens. Vol. 44, No. 5, 1209-1238, doi:10.1109/TGRS.2006.869987.

[3] P.F. Levelt et al. (2006), The Ozone Monitoring Instrument, IEEE Trans. Geo. Rem. Sens. Vol. 44, No. 5, 1093 1101, doi:10.1109/TGRS.2006.872333.

[4] G.H.J. van den Oord et al. (2006), OMI Level0 to $1 b$ Processing and Operational Aspects, IEEE Trans. Geo. Rem. Sens. Vol. 44, No. 5, 1380-1397, doi:10.1109/TGRS.2006.872935.

[5] R.T. Jongma et al. (2006), Sensitivity analyses of a new SWIR-channel measuring tropospheric $\mathrm{CH}_{4}$ and CO from space, these SPIE proceedings, manuscript no. 6302-41 